UDC 612.821:316.624

LBC 28.707.3

\title{
SYSTEMATIZATION OF THE FACTORS OF FORMATION OF SOCIAL DEVIATIONS ${ }^{1}$
}

\author{
Yuliya A. Shatyr \\ Volgograd State University, Volgograd, Russian Federation \\ Irina G. Mulik \\ Volgograd State Agrarian University, Volgograd, Russian Federation \\ Irina V. Ulesikova \\ Volgograd State University, Volgograd, Russian Federation \\ Vladimir V. Delaru \\ Volgograd State Medical University, Volgograd, Russian Federation \\ Aleksandr B. Mulik \\ Volgograd State University, Volgograd, Russian Federation
}

\begin{abstract}
The article presents the results theoretical analysis and experimental research of risk factors for developing specific forms of deviant behavior. The main theories explaining the reasons for the formation of deviant behavior are described. The absence of an orderly system of cause-effect relationships that determine the complex conditioning specific deviations by stable combinations of phenotypic traits of a person is revealed. The undertaken analysis of - scientific literature made it possible to correlate the combination of accentuations of temperament and character with ㄱ. separate forms of deviant behavior and to develop an appropriate reference table on this basis. The study of the i conjugation of psychophysiological and psychological characteristics with actually manifested behavioral abnormalities revealed a number of combinations of phenotypic features characteristic of persons with suicidal tendencies, alcoholism, prostitution and vagrancy, convicted of theft and violent actions. The first group of combinations combines a high level of reactivity, choleric temperament, hypertension. The coincidence of the presented indicators indicates a tendency to acute affective reactions and situationally caused pathological behavioral disorders that provoke alcoholism, anesthesia, emancipation shoots. The second group of combinations of deviation risk indicators combines a high level of reactivity, 옹 choleric temperament, excitability. It is characterized by a high probability of occurrence of acute affective reactions. The ज्ञ third group of combinations includes a high level of reactivity, melancholic temperament, rigidity, dysthymic. With this c. combination of features present affective suicide risk, due to the tendency to depressive reactions. The fourth group of combinations of risk indicators of deviations combines low level of reactivity, phlegmatic temperament, dysthymic. This combination of personal characteristics determines the internal predisposition to true suicide. The completed studies justify the need for an integrated approach to assess the risk of manifestation of a specific deviation, taking into account the combination of functional, psychophysiological, psychological and social characteristics of a person.

Key words: social deviations, socio-psychological status, accentuations, factors of social deviation formation, prediction of deviant behavior.

УДК $612.821: 316.624$

ББК 28.707 .3

\section{СИСТЕМАТИЗАЦИЯ ФАКТОРОВ ФОРМИРОВАНИЯ СОЦИАЛЬНЫХ ДЕВИАЦИЙ ${ }^{1}$}

Юлия Александровна Шатыр

Волгоградский государственный университет, г. Волгоград, Российская Федерация 


\title{
Ирина Геннадьевна Мулик
}

Волгоградский государственный аграрный университет, г. Волгоград, Российская Федерация

\section{Ирина Владимировна Улесикова}

Волгоградский государственный университет, г. Волгоград, Российская Федерация

\section{Владимир Владимирович Деларю}

Волгоградский государственный медицинский университет, г. Волгоград, Российская Федерация

\section{Александр Борисович Мулик}

Волгоградский государственный университет, г. Волгоград, Российская Федерация

\begin{abstract}
Аннотация. В статье изложены результаты теоретического анализа и экспериментального исследования факторов риска развития конкретных форм девиантного поведения. Представлены основные теории, объясняющие причины формирования отклоняющегося поведения. Выявлено отсутствие упорядоченной системы причинно-следственных связей, определяющих комплексную обусловленность конкретных девиаций устойчивыми сочетаниями фенотипических признаков человека. Предпринятый анализ научной литературы позволил соотнести сочетания акцентуаций темперамента и характера с отдельными формами девиантного поведения и разработать на этой основе соответствующую справочную таблицу. Изучение сопряженности психофизиологических и психологических характеристик с реально проявляемыми поведенческими отклонениями выявило ряд комбинаций фенотипических признаков, характерных для лиц с суицидальными наклонностями, страдающих алкоголизмом, занимающихся проституцией и бродяжничеством, осужденных за кражи и насильственные действия. Первая группа комбинаций объединяет высокий уровень реактивности, холерический темперамент, гипертимность. Совпадение представленных показателей свидетельствует о склонности к ситуативно обусловленным патологическим нарушениям поведения и острым аффективным реакциям, провоцирующим алкоголизацию, наркотизацию, эмансипационные побеги. Вторая группа комбинаций показателей риска девиаций объединяет высокий уровень реактивности, холерический темперамент, возбудимость. Характеризуется высокой вероятностью возникновения острых аффективных реакций. Третья группа комбинаций включает в себя высокий уровень реактивности, меланхолический темперамент, ригидность, дистимичность. При данном сочетании признаков присутствует риск аффективного суицида, обусловленного склонностью к депрессивным реакциям. Четвертая группа сочетаний показателей риска девиаций объединяет низкий уровень реактивности, флегматический темперамент, дистимичность. Данная комбинация личностных характеристик обусловливает внутреннюю предрасположенность к истинному суициду. Выполненные исследования обосновывают необходимость применения комплексного подхода к оценке риска проявления конкретной девиации, учитывающего сочетания функциональных, психофизиологических, психологических и социальных характеристик человека.
\end{abstract}

Ключевые слова: социальные девиации, социально-психологический статус, акцентуации, факторы формирования социальных девиаций, прогнозирование девиантного поведения.

К настоящему времени в науке и практике накоплен значительный объем теоретических и эмпирических данных о биологической, психологической и социальной обусловленности девиантного поведения человека. В рамках биологического подхода наиболее популярна эволюционная теория Ч. Дарвина, позже развитая в исследованиях Р. Фишера и Дж. Миллера. Данная теория обосновывает востребованность деструктивных взаимодействий между членами микросоциума, например, при недостатке пищи или дефиците брачных партнеров, что способствует повышению репродукции при ограниченности ресурсов в популяции [9].
Австрийский этолог К. Лоренц констатировал биологическую целесообразность существования механизма внутривидовой агрессии у животных. С его точки зрения, аналогичным образом внутривидовая агрессия проявляется и у человека, представляя собой самопроизвольное инстинктивное стремление к оптимизации удовлетворения различных потребностей. Однако, оправдывая целесообразность агрессивного поведения, К. Лоренц выдвинул гипотезу о том, что кроме врожденного инстинкта борьбы все живые существа наделены способностью подавлять свои агрессивные побуждения. Это обеспечивает более гиб- 
кое приспособление вида и сохранение генофонда при естественном отборе. В данной концепции агрессивный инстинкт является адаптивным, регулируя внутривидовые отношения в естественных условиях жизнедеятельности человека [8]. По мнению английского антрополога Р. Ардри, в процессе эволюции, вследствие естественного отбора, появился новый тип биологического и социального взаимодействия: охотника и жертвы. При этом охотники «убивали, чтобы выжить», «нападали, чтобы не голодать». Склонность к агрессии, по утверждению Р. Ардри, запрограммирована на генетическом уровне, она социально подкреплена и неизбежна в человеческом обществе. Наличие оружия, способного поражать на расстоянии, а также вербальных каналов коммуникации лишь провоцируют реализацию агрессии в войнах и социальном насилии [5].

Представители психологических и социологических концепций отказались от трактовки девиации как инстинктивного поведения, определяя ее как реагирование личности на внезапно изменившиеся условия внешней среды.

А. Адлер полагал, что возникновение девиации обусловлено конкуренцией между индивидами в первоочередном удовлетворении потребностей в различных аспектах жизнедеятельности. При этом он считал, что девиация отчасти является осознаваемой реакцией на раздражитель и в своем проявлении может трансформироваться в социально приемлемые формы, например в спортивные состязания [1].

Одной из наиболее популярных в рамках бихевиористского подхода является теория социального научения, полагающая, что проявление человеческой девиантности тесно связано с сопутствующими социальными условиями, так или иначе провоцирующими развитие отклоняющегося поведения [2]. Изменение условий способно ослабить или предотвратить формирование девиации. Сторонниками теории научения являются Р. Бэрон и Д. Ричардсон, определяя в качестве основных источников девиации семью, опыт взаимодействия с окружающими и масс-медиа [4]. К предпосылкам формирования девиации они относят фрустрацию, тревогу, раздражительность, эмоциональную чувствительность, тенденцию к стыду, авторитаризм, враждебность, подстрекательство со стороны окружающих.
Э. Дюркгейм воспринимал социальные отклонения как следствие нормативно-ценностной дезинтеграции общества. Дальнейшее развитие его идеи получили в работах В. Парето и Л. Козера, рассматривающих противоречия между классами и различными социальными силами в качестве оснований для формирования склонности к девиантному поведению [1].

На фоне всесторонней разработанности теорий развития поведенческих и социальных отклонений отсутствует системное методическое обеспечение оценки и прогноза риска развития конкретных форм девиантного поведения человека. По результатам анализа научной литературы было определено наличие в основном психологических маркеров склонности человека к отдельным формам девиации. Наиболее разработаны в качестве показателей риска развития различных вариантов отклоняющегося поведения акцентуации темперамента и характера [6]. Выявлено, что для каждого типа акцентуаций в подростковом возрасте характерно формирование определенной специфики сложных форм поведения [7].

Предпринятый теоретический анализ сочетаний различных векторов социальной девиации с акцентуациями темперамента и характера, представленных в работах К. Леонгарда [6], А.Е. Личко [7], С.А. Беличевой [3] позволил выявить их типичные взаимосвязи.

Так, гипертимы стремятся к лидерству среди сверстников, а потому из-за легкомыслия, жажды развлечений, тяги к риску становятся вдохновителями групповых правонарушений. Чрезмерная живость может легко переходить к крайним формам раздражительности. У них наблюдается игнорирование этических норм, утрата чувства долга и способности к раскаянию. Проявляют интерес не только к потреблению алкоголя, но и к широкому кругу наркотических веществ. У представителей гипертимного типа нередко наблюдается «первичный поисковый полинаркотизм». Если эта весьма любознательная, творческая личность находится в состоянии интеллектуального голода, то для нее будет весьма заманчивым заполнить эту пустоту переживанием необычных, новых, ярких и неизведанных ощущений. В выборе знакомств 
гипертимы проявляют крайнюю неразборчивость. Авантюрность гипертимных подростков толкает их на незаконные сделки, мелкие кражи, а отсутствие застенчивости и легкость установления контактов способствуют ранним сексуальным связям. Совпадение представленных поведенческих проявлений свидетельствует о склонности гипертимов к острым аффективным реакциям и ситуативно обусловленным патологическим нарушениям поведения (ранняя алкоголизация, наркотизация, эмансипационные побеги).

Возбудимые люди часто производят впечатление примитивной личности. Уровень организации их психики включает в себя два варианта видения мира: его делят на чужой, то есть враждебный, вызывающий чувство опасности, а следовательно - агрессии, и свой, который, наоборот, приводит к состоянию самозащищенности, психического равновесия. Решающими для образа жизни и поведения возбудимой личности являются инстинкты, влечения и неконтролируемые побуждения. Влечения здесь выступают как стремление к разрядке именно физического плана, имея при этом паталогическую власть над возбудимой личностью. Наблюдается пробуждение древнего инстинкта к бродяжничеству, к жажде переживаний. Возбудимые личности постоянно нуждаются в аффективной разрядке. Наращивание аффекта инициирует проявление агрессии. Присутствует склонность к периодическому возникновению злобно-тоскливого настроения. Иногда возникает риск аутоагрессии, склонность к алкоголизации. В сексуальной сфере импульсивны, неразборчивы в половых связях. При сопутствующих обстоятельствах возможны кражи. В детском возрасте склонны к немотивированным побегам из дома.

Эмотивные личности характеризуются чувствительностью и глубокими реакциями в области тонких эмоций. Наблюдается склонность к внешним проявлениям реакций. Выраженная чувствительность провоцирует душевные потрясения и реактивную депрессию. На пике напряжения возможны попытки суицида. Здесь же наблюдается феномен сверхкомпенсации, когда индивид готов идти на противоправные действия, лишь бы его заметили. Эмотивные люди стремятся к вниманию окружающих, пусть даже путем превращения себя в отьявленного нарушителя спокойствия.

Индивиды, проявляющие выраженную застреваемость, характеризуются чрезмерной подозрительностью, патологической ревностью, что в самом худшем случае может привести к убийству. Всякая неудача вызывает злобу в отношении более удачливых людей, особенно если эта неудача является следствием собственной несостоятельности. Присуще культивирование грубой силы. Если мир отверг меня, то я должен поступать также в соответствии с законами силы, действуя в рамках и большого, и малого мира.

Циклоиды не склонны к нарушению поведения, но могут проявлять склонность к алкоголизации в период подъема настроения. Причем у таких людей радостные события вызывают не только положительные эмоции, но и общую психоэмоциональную активацию, жажду деятельности, смену идей (чрезмерная подвижность, крайняя неуравновешенность). Печальные события вызывают подавленность, а также замедленность реакции и мышления, суицидальные настроения.

Демонстранты склонны к подчинению, к полному подавлению своего «я», обладают даром «отрекаться от себя», вживаясь в ту роль, которая нравится лидеру. Демонстрант будет таким, каким его хотят видеть, поэтому, попадая в асоциальную группу, он принимает ее правила игры, особенно если учесть, что у него мало развит этический комплекс. Его приспособительность выражается в избирательности выгодных ему людей. Претендует на исключительное положение среди сверстников, что обусловливает его предрасположенность к потреблению стимуляторов с целью обрести уверенность в себе, в своих силах и способностях, пробудить самоуверенность и бесстрашие. Обладает упорством в достижении признания.

Дистим имеет склонность к сосредоточению на мрачных сторонах жизни и тем сильнее ощущает неудовлетворенность от ее отрицательных моментов. При этом дистимичные личности отличаются повышенной устойчивостью в отношении алкоголизации и наркотизации. Они характеризуются стеснительностью и робостью, что затрудняет общение со сверстниками. Присущий им комплекс не- 
полноценности, заниженная самооценка и основывающаяся на них реакция гиперкомпенсации не влекут за собой аддиктивного поведения за исключением ситуативно возникающих суицидальных настроений.

Экзальтированные люди отличаются крайней впечатлительностью по поводу печальных событий, часто доводящей их до отчаяния, что может провоцировать суицидальные действия. На почве грустных и тревожных переживаний, вызывающих психологическое угнетение, возникает потребность в потреблении психоактивных веществ.

Тревожные личности в одном случае характеризуются робостью и покорностью, а в другом - внутренней неуверенностью в себе. В сочетании с ригидностью может проявляться мстительность, а в сочетании с возбудимостью - вспыльчивость, что, в свою очередь, на фоне тревожности исключает агрессию, но провоцирует склонность к кражам.

Педантический тип личности, отличающийся доминированием идеи порядка и аккуратности, как правило, наделен ригидностью, склонностью к переживаниям и нерешительностью. Люди педантического типа избегают конфликтов, но в редких случаях проявляется риск суицида.

Обобщение представленных данных позволило соотнести сочетания акцентуаций с конкретными формами девиантного поведения и разработать на этой основе соответствующую справочную таблицу (табл. 1).
Кроме того, было предпринято экспериментальное исследование сопряженности психофизиологических и психологических характеристик сложных, в том числе девиантных, форм поведения в группах благополучных лиц (138 студентов Волгоградского государственного университета), а также в группах трудных подростков и молодежи, проявивших девиантное поведение или совершивших правонарушения и преступления (30 школьников трудных подростков, 44 условно осужденных жителя города Волгограда и 25 преступников и правонарушителей, содержавшихся в Центре временной изоляции города Волгограда). Работа выполнялась при условии получения письменного информированного согласия испытуемых, с соблюдением регламента «Всеобщей декларации о биоэтике и правах человека» в части статей 5, 6 и 7.

У всех исследуемых посредством приборного тестирования определялся индивидуальный уровень общей неспецифической реактивности организма (далее - УОНРО) [10]. Типологические особенности высшей нервной деятельности, экстраверсию, нейротизм, акцентуации темперамента и характера оценивали стандартными методами бланкового тестирования [11]. Для ретроспективной оценки сложных, в том числе девиантных, форм поведения испытуемых использовали анализ документов и экспертные характеристики специалистов: преподавателей, психологов, сотрудников правоохранительных органов.

Таблицุа 1

Специфика проявления девиантного поведения человека в зависимости от наличия выраженных акцентуаций

\begin{tabular}{|l|c|c|c|c|c|c|c|c|c|c|}
\hline \multicolumn{1}{|c|}{ Формы девиации } & \multicolumn{7}{|c|}{ Акцентации } \\
\hline & Г & Д & В & Т & Р & Ц & Эк & Эм & Дис & П \\
\hline Агрессия & & & & & & & & & & \\
\hline Грубое насилие & & & & & & & & & & \\
\hline Убийство & & & & & & & & & & \\
\hline Суицид & & & & & & & & & & \\
\hline Кражи & & & & & & & & & & \\
\hline Мошенничество & & & & & & & & & & \\
\hline Алкоголизм, наркомания & & & & & & & & & & \\
\hline Бродяжничество & & & & & & & & & & \\
\hline Проституция & & & & & & & & & & \\
\hline Ранние сексуальные связи & & & & & & & & & & \\
\hline Мстительность & & & & & & & & & & \\
\hline Отсутствие раскаяния & & & & & & & & & & \\
\hline
\end{tabular}


Вначале всех испытуемых разделили на две группы: «благополучную» и «девиантную», одновременно произведя оценку типологических характеристик высшей нервной деятельности, экстраверсии и нейротизма у обследуемых лиц. Было выявлено, что по большинству исследуемых показателей выраженных различий между группами наблюдения не имеется. Отмечено значимое преимущество $(p<0,05)$ подвижности нервных процессов и нейротизма в группе лиц с девиантным поведением относительно группы испытуемых без признаков девиации.

Затем группу испытуемых, характеризующуюся девиантным поведением, дополнительно разделили на шесть подгрупп, в зависимости от фактически выявленных форм девиации: суицид, бродяжничество, проституция, потребление психоактивных веществ, кражи, физическое насилие. По каждому наблюдаемому дополнительно выполнили качественную оценку типа высшей нервной деятельности (холерик, меланхолик, сангвиник, флегматик) и УОНРО (высокий, средний, низкий). Относительное распределение представителей выделенных групп девиантного поведения по УОНРО с учетом темперамента, представлено на рисунке.
Детальное исследование типологических особенностей высшей нервной деятельности в выделенных группах УОНРО выявило ряд характерных взаимосвязей. Так, в группе лиц, занимающихся проституцией, было зафиксировано преобладание сангвиников. Большинство потребителей психоактивных веществ отличаются холерическим темпераментом. Индивиды, проявившие суицидальные наклонности, в своем большинстве являются холериками или меланхоликами. Для лиц, склонных к бродяжничеству, характерны чрезмерная подвижность, а также выраженный дисбаланс между силами возбуждения и торможения нервных процессов.

С целью детализированной характеристики психологических предпосылок конкретных форм девиантного поведения была выполнена оценка акцентуаций у представителей ранее выделенных шести групп наблюдения (суицид, бродяжничество, проституция, потребление психоактивных веществ, кражи, физическое насилие). Определено, что склонностью к суициду отличаются лица с выраженной возбудимостью, экзальтированностью и эмотивностью. Бродяжничеством занимаются лица с ярко выраженной возбудимостью

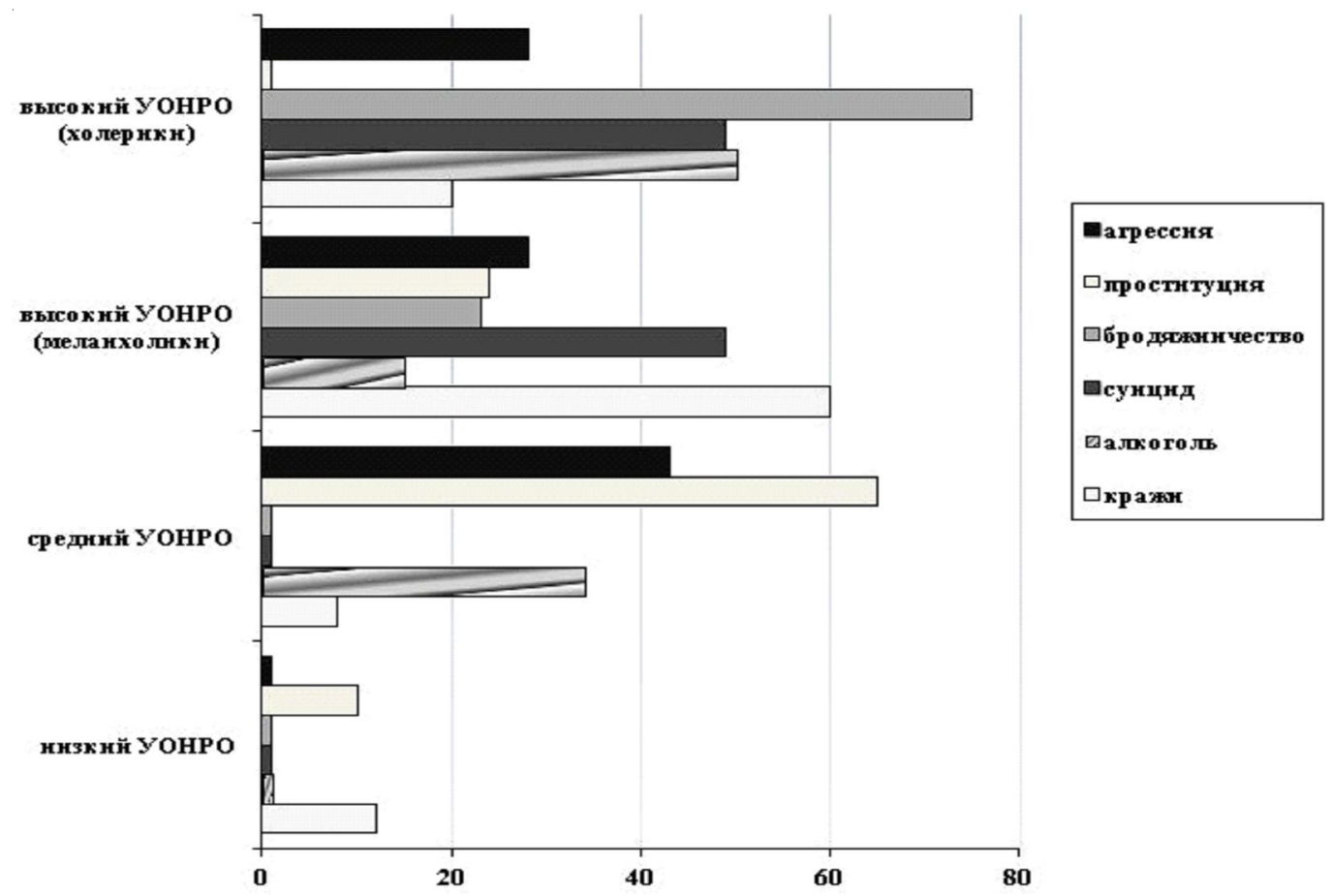

Выраженность типологических особенностей ВНД, экстраверсии и нейротизма у «благополучных» и «девиантных» испытуемых 


\section{СОЦИОЛОГИЯ И СОЦИАЛЬНЫЕ ТЕХНОЛОГИИ}

и дистимичностью. Склонность к занятиям проституцией испытывают девушки с повышенным уровнем возбудимости, дистимичности, гипертимности, циклотимичности. Потребители психоактивных веществ обладают выраженной возбудимостью, дистимичностью и гипертимностью. Склонностью к кражам, агрессивным действиям характеризуются лица с выраженной возбудимостью, дистимичностью, ригидностью и гипертимностью.

Сравнительный анализ результатов теоретического исследования и фактического проявления акцентуаций, характерных для различных форм девиантного поведения, выявил неоднозначность их соотношений. Обобщив весь комплекс изученных показателей, представлялось целесообразным выделить и сгруппировать психофизиологические и психологические факторы потенциального риска развития различных форм девиантного поведения. При этом были определены четыре группы комбинаций исследуемых показателей риска формирования девиаций, объединяющих УОНРО, тип темперамента, наличие акцентуаций и выраженность экстраверсии (табл. 2).

В результате предпринятых исследований определены типичные сочетания функциональных, психофизиологических и психологических признаков потенциального риска развития различных форм девиантного поведения. При этом представляется целесообразным выделить ряд принципиальных моментов, конкретизирующих комплексный характер эндогенных факторов формирования сложных форм поведения. Прежде всего, необходимо констатировать системность проявления фенотипических признаков организма, обеспечивающих индивидуализацию психической деятельности. Определен интегральный характер организации общей неспецифической реактив- ности организма, персонализирующей психоэмоциональную компоненту сознательного и бессознательного в поведении человека. Учет выделенных комбинаций физиологических, психофизиологических и психологических качеств позволяет прогнозировать риски развития основных форм девиантного поведения человека.

\section{ПРИМЕЧАНИЕ}

1 Работа выполнена при финансовой поддержке РФФИ и Администрации Волгоградской области в рамках реализации Проекта № 17-16-34019 «Поведенческие риски инфицирования ВИЧ и парентеральными гепатитами в организованных контингентах учащейся молодежи».

\section{СПИСОК ЛИТЕРАТУРЫ}

1. Андреева, Г. М. Современная социальная психология на Западе / Г. М. Андреева, Н. Н. Богомолова, Л. А. Петровская. - М. : Изд-во Моск. ун-та, 1978. -272 c.

2. Бандура, А. Теория социального научения / А. Бандура. - СПб. : Евразия, 2000. - 292 с.

3. Беличева, С. А. Основы превентивной психологии / С. А. Беличева. - М. : Ред.-изд. центр Консорциума «Социальное здоровье России», 1994. $222 \mathrm{c}$.

4. Бэрон, Р. Агрессия / Р. Бэрон, Д. Ричардсон. - СПб. : Питер, 2001. - 352 с.

5. Ильин, Е. П. Дифференциальная психология мужчины и женщины / Е. П. Ильин. - СПб. : Питер, 2003. - 544 c.

6. Леонгард, К. Акцентуированные личности : пер. с нем. / К. Леонгард.- Ростов н/Д : Феникс, 1997. $-544 \mathrm{c}$.

7. Личко, А. Е. Патохарактерологический диагностический опросник для подростков и опыт его практического применения / А. Е. Личко, М. Я. Иванов. - М. : Фолиум, 1995. - 64 с.

Таблииа 2

\section{Варианты проявления некоторых социальных девиаций в зависимости от сочетаний показателей фенотипа}

\begin{tabular}{|l|c|c|c|c|}
\hline \multirow{2}{*}{ Социальные девиации } & \multicolumn{4}{|c|}{ Показатели фенотипа } \\
\cline { 2 - 5 } & $\begin{array}{c}\text { Уровень } \\
\text { реактивности }\end{array}$ & Темперамент & Акцентуации & $\begin{array}{c}\text { Экстраверсия- } \\
\text { интроверсия }\end{array}$ \\
\hline $\begin{array}{l}\text { Алкоголизация } \\
\text { и наркотизация }\end{array}$ & Высокий & Холерический & Гипертимность & Экстраверсия \\
\hline Физическая агрессия & Высокий & Холерический & Возбудимость & Экстраверсия \\
\hline Аффективный суицид & Высокий & Меланхолический & Ригидность & Интроверсия \\
\hline Истинный суицид & Низкий & Флегматический & Дистимичность & Интроверсия \\
\hline
\end{tabular}


8. Лоренц, К. Агрессия (так называемое «зло») / К. Лоренц. - М. : Прогресс : Универс, 1994. -219 с.

9. Марков, А. В. Происхождение человека и половой отбор / А. В. Марков // Историческая психология и социальная история. - 2011. - № 2. - С. 30-35.

10. Мулик, А. Б. Уровень общей неспецифической реактивности организма человека : монография / А. Б. Мулик, М. В. Постнова, Ю. А. Мулик. - Волгоград : Волгогр. науч. изд-во, 2009. - 224 с.

11. Психологические тесты : в 2 т. / под ред. А. А. Карелина. - М. : Изд-во ВЛАДОС-ПРЕСС, 2007.- T. $1 .-312 \mathrm{c}$.

\section{REFERENCES}

1. Andreeva G.M., Bogomolova N.N., Petrovskaya L.A. Sovremennaya sotsialnaya psikhologiya na Zapade [Modern Social Psychology in the West]. Moscow, Izd-vo MGU, 1978. 272 p.

2. Bandura A. Teoriya sotsialnogo naucheniya [The Theory of Social Learning]. Saint Petersburg, Evraziya Publ., 2000. 292 p.

3. Belicheva S.A. Osnovy preventivnoy psikhologii [The Fundamentals of Preventive Psychology]. Moscow, Sotsialnoe zdorovye Rossii Publ., 1994. 222 p.

4. Beron R. Agressiya [Aggression]. Saint Petersburg, Piter Publ., 2001.352 p.
5. Ilyin E.P. Differentsialnaya psikhologiya muzhchiny i zhenshchiny [Differential Psychology of Man and Woman]. Saint Petersburg, Piter Publ., 2003. $544 \mathrm{p}$.

6. Leongard K. Aktsentuirovannye lichnosti [Accentuated Persons]. Rostov-on-Don, Feniks Publ., 1997. $544 \mathrm{p}$.

7. Lichko A.E. Patokharakterologicheskiy diagnosticheskiy oprosnik dlya podrostkov $i$ opyt ego prakticheskogo primeneniya [Patocharacterological Diagnostic Questionnaire for Adolescents and the Experience of Its Practical Application]. Moscow, Folium Publ., 1995. $64 \mathrm{p}$.

8. Lorents K. Agressiya (tak nazyvaemoe "zlo") [Aggression (the So-Called "Evil")]. Moscow, Progress, Univers Publ., 1994. 219 p.

9. Markov A.V. Proiskhozhdenie cheloveka i polovoy otbor [Man Origins and Sexual Selection]. Istoricheskaya psikhologiya i sotsialnaya istoriya, 2011, no. 2, pp. 30-35.

10. Mulik A.B., Postnova M.V., Mulik Yu.A. Uroven obshchey nespetsificheskoy reaktivnosti organizma cheloveka: monografiya [Level of General Nonspecific Reactivity of the Human Body: Monograph]. Volgograd, Volgogradskoe nauchnoe izdvo, 2009. 224 p.

11. Karelin A.A., ed. Psikhologicheskie testy. $V 2 t$. [Psychological Tests. In 2 vols.]. Moscow, VLADOS-PRESS, 2007. $312 \mathrm{p}$.

\section{Information about the Authors}

Yuliya A. Shatyr, Candidate of Biological Sciences, Associate Professor, Senior Researcher, Laboratory of Psychophysiology, Volgograd State University, Prosp. Universitetsky, 100, 400062 Volgograd, Russian Federation, yuliashatyr@gmail.ru.

Irina G. Mulik, Senior Lecturer, Department of Pedagogy and Methodology of Professional Training, Volgograd State Agrarian University, Prosp. Universitetsky, 26, 400002 Volgograd, Russian Federation, mulikig@mail.ru.

Irina V. Ulesikova, Laboratory Assistant, Laboratory of Psychophysiology, Volgograd State University, Prosp. Universitetsky, 100, 400062 Volgograd, Russian Federation, ulesikovairina@mail.ru.

Vladimir V. Delaru, Doctor of Sociological Sciences, Professor, Department of General and Clinical Psychology, Volgograd State Medical University, Pavshikh Bortsov Sq., 1, 400131 Volgograd, Russian Federation, vvdnvd@gmail.com.

Aleksandr B. Mulik, Doctor of Biological Sciences, Professor, Director of Research and Education Center of Physiology and Homeostasis, Volgograd State University, Prosp. Universitetsky, 100, 400062 Volgograd, Russian Federation, mulikab@mail.ru, mulik@volsu.ru.

\section{Информация об авторах}

Юлия Александровна Шатыр, кандидат биологических наук, доцент, старший научный сотрудник лаборатории психофизиологии, Волгоградский государственный университет, просп. Университетский, 100, 400062 г. Волгоград, Российская Федерация, yuliashatyr@gmail.ru. 


\section{СОЦИОЛОГИЯ И СОЦИАЛЬНЫЕ ТЕХНОЛОГИИ}

Ирина Геннадьевна Мулик, старший преподаватель кафедры педагогики и методики профессионального обучения, Волгоградский государственный аграрный университет, просп. Университетский, 26, 400002 г. Волгоград, Российская Федерация, mulikig@mail.ru.

Ирина Владимировна Улесикова, лаборант лаборатории психофизиологии, Волгоградский государственный университет, просп. Университетский, 100, 400062 г. Волгоград, Российская Федерация, ulesikovairina@mail.ru.

Владимир Владимирович Деларю, доктор социологических наук, профессор кафедры общей и клинической психологии, Волгоградский государственный медицинский университет, пл. Павших борцов, 1, 400131 г. Волгоград, Российская Федерация, vvdnvd@gmail.com.

Александр Борисович Мулик, доктор биологических наук, профессор, руководитель научно-образовательного центра физиологии гомеостаза, Волгоградский государственный университет, просп. Университетский, 100, 400062 г. Волгоград, Российская Федерация, mulikab@mail.ru, mulik@volsu.ru. 